Supplement of Geosci. Model Dev., 15, 1899-1911, 2022

https://doi.org/10.5194/gmd-15-1899-2022-supplement

(C) Author(s) 2022. CC BY 4.0 License.

(c) (i)

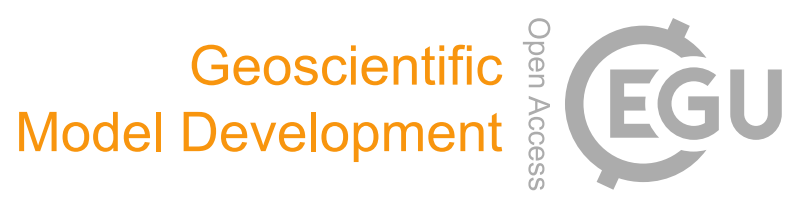

Supplement of

\title{
Building a machine learning surrogate model for wildfire activities within a global Earth system model
}

Qing Zhu et al.

Correspondence to: Qing Zhu (qzhu@lbl.gov)

The copyright of individual parts of the supplement might differ from the article licence. 
1

4

\begin{tabular}{lllll}
\hline Dataset name & $\begin{array}{l}\text { Temporal } \\
\text { range }\end{array}$ & $\begin{array}{l}\text { Spatial } \\
\text { resolution }\end{array}$ & $\begin{array}{l}\text { Burned area, } \\
\text { mean (std) }\end{array}$ & Citations \\
\hline GFEDv4s & $1997-2015$ & 0.25 degree & $455(39)$ & $\begin{array}{l}\text { (Van Der Werf, Randerson } \\
\text { et al. 2017) }\end{array}$ \\
\hline Fire_CCI51 & $2001-2019$ & 0.25 degree & $476(26)$ & $\begin{array}{l}\text { (Lizundia-Loiola, Otón et } \\
\text { al. 2020) }\end{array}$ \\
\hline Fire_CCILT11 & $1982-2018$ & 0.25 degree & $484(20)$ & $\begin{array}{l}\text { (Lizundia-Loiola, Pettinari } \\
\text { et al. 2018) }\end{array}$ \\
\hline MCD64 & $2001-2019$ & 0.25 degree & $424(35)$ & $\begin{array}{l}\text { (Giglio, Boschetti et al. } \\
\text { 2018) }\end{array}$ \\
\hline Fire_Atlas & $2003-2016$ & $\begin{array}{l}0.25 \times 0.25 \\
\text { degree }\end{array}$ & $459(43)$ & $\begin{array}{l}\text { (Andela, Morton et al. } \\
\text { 2019) }\end{array}$ \\
\hline
\end{tabular}

5 Note: the long-term average global burned area was calculated using data with the same

6 overlapping temporal range (2003-2015), unit Mha $\mathrm{yr}^{-1}$

\section{Supplementary Material}

Table S1. Burned area datasets used in this study 


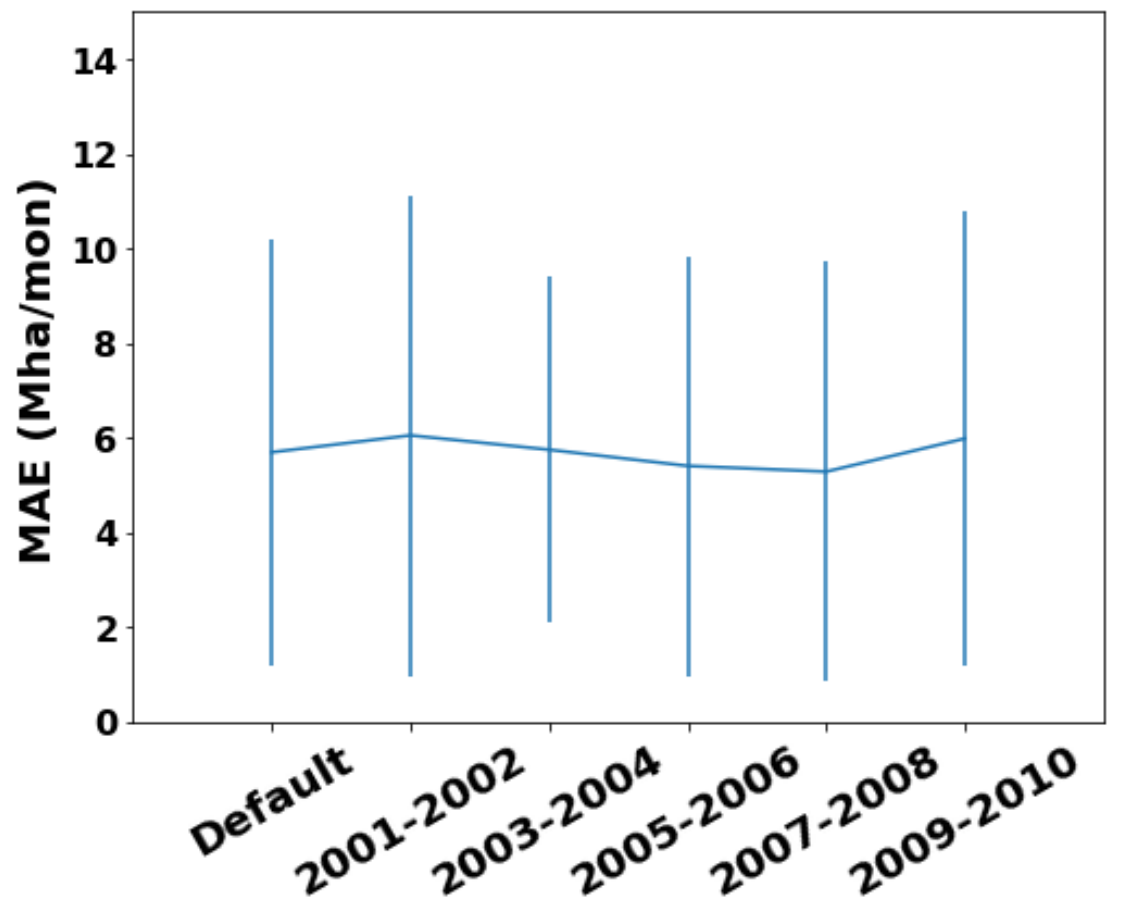

10 Figure S1. Model performance evaluated with testing datasets of default (20\% randomly

11 selected samples), or fixed to 2001-2002 period, 2003-2004 period, 2005-2006 period, 2007-

122008 period, and 2009-2010 periods (the rest of the dataset was used as a training dataset.).

13
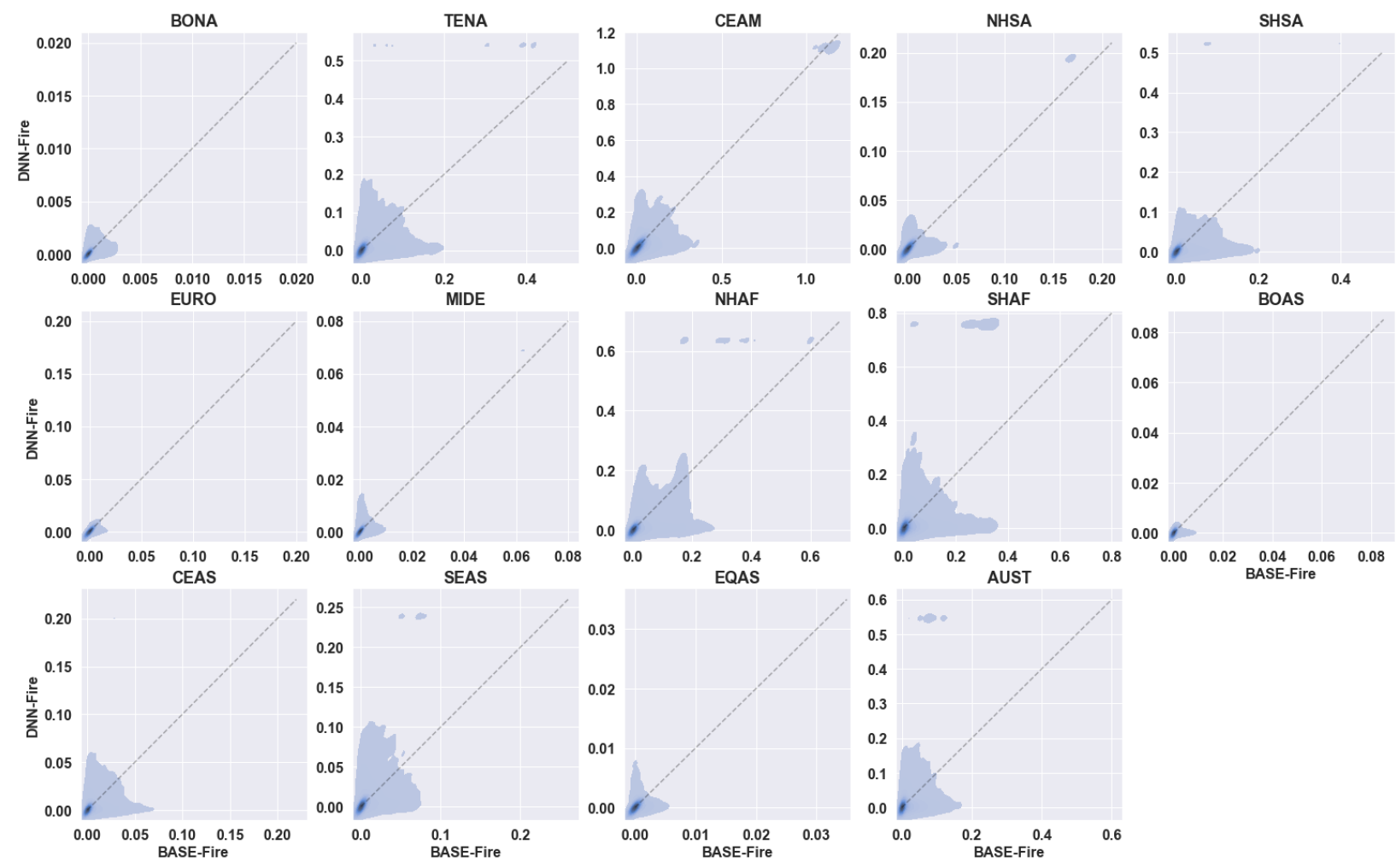
15 Figure S2. Performance of surrogate model (DNN-Fire) compared with ELMv1 process-based model (BASE-Fire).
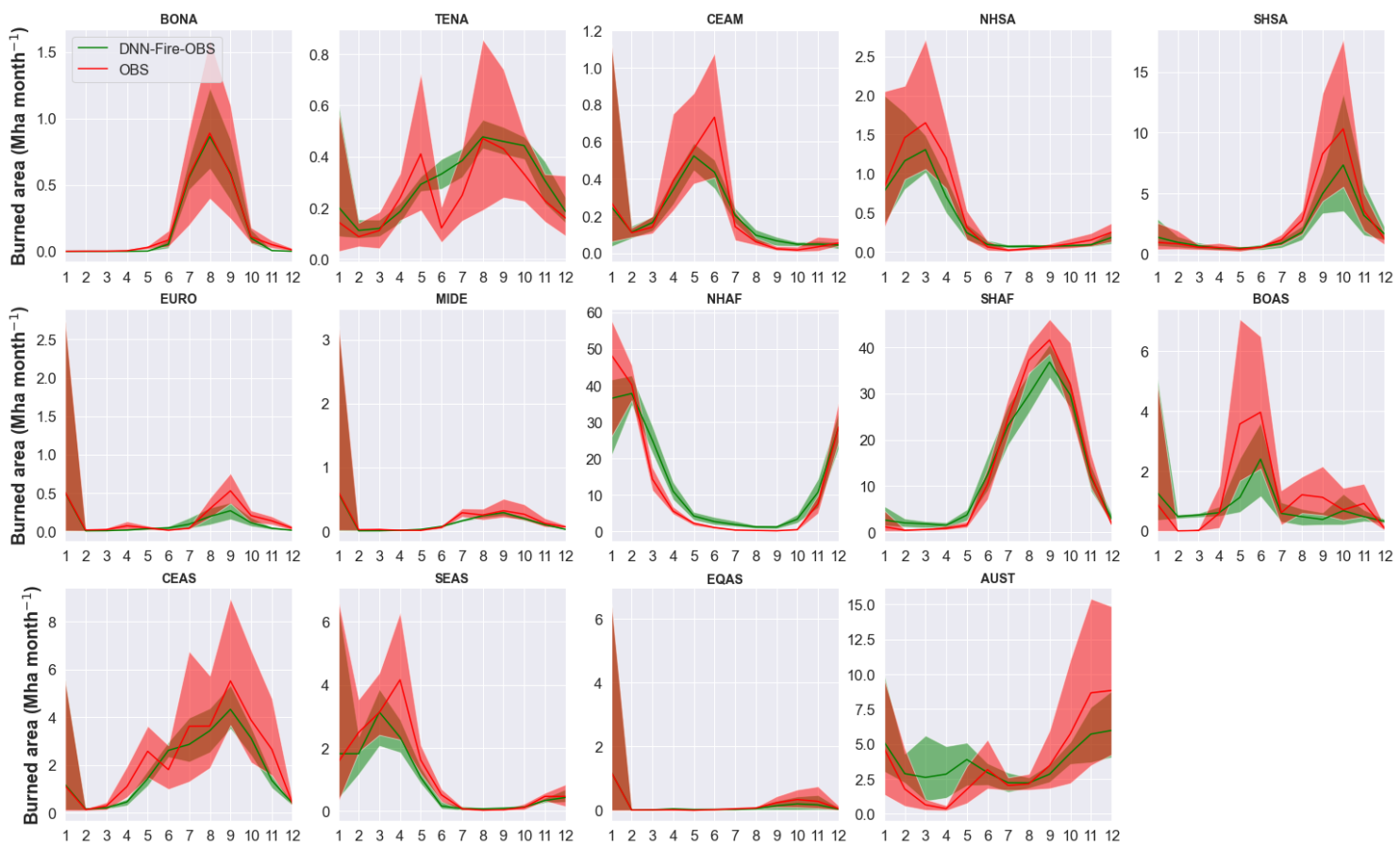

Figure S3. Seasonal cycles of fine-tuned Deep Neural Network wildfire model (DNN-Fire-OBS) and observations over 14 GFED fire regions.

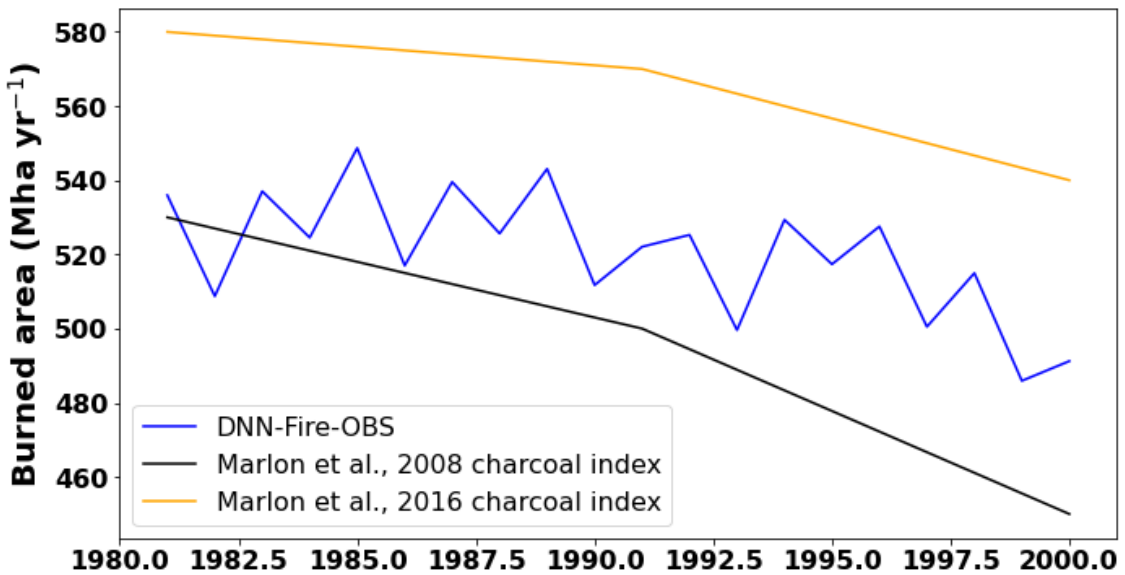

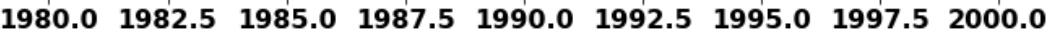

Year

Figure S4. Comparison of DNN-Fire-OBS model simulated global burned area during 19811999 with two charcoal index inferred burned area. 


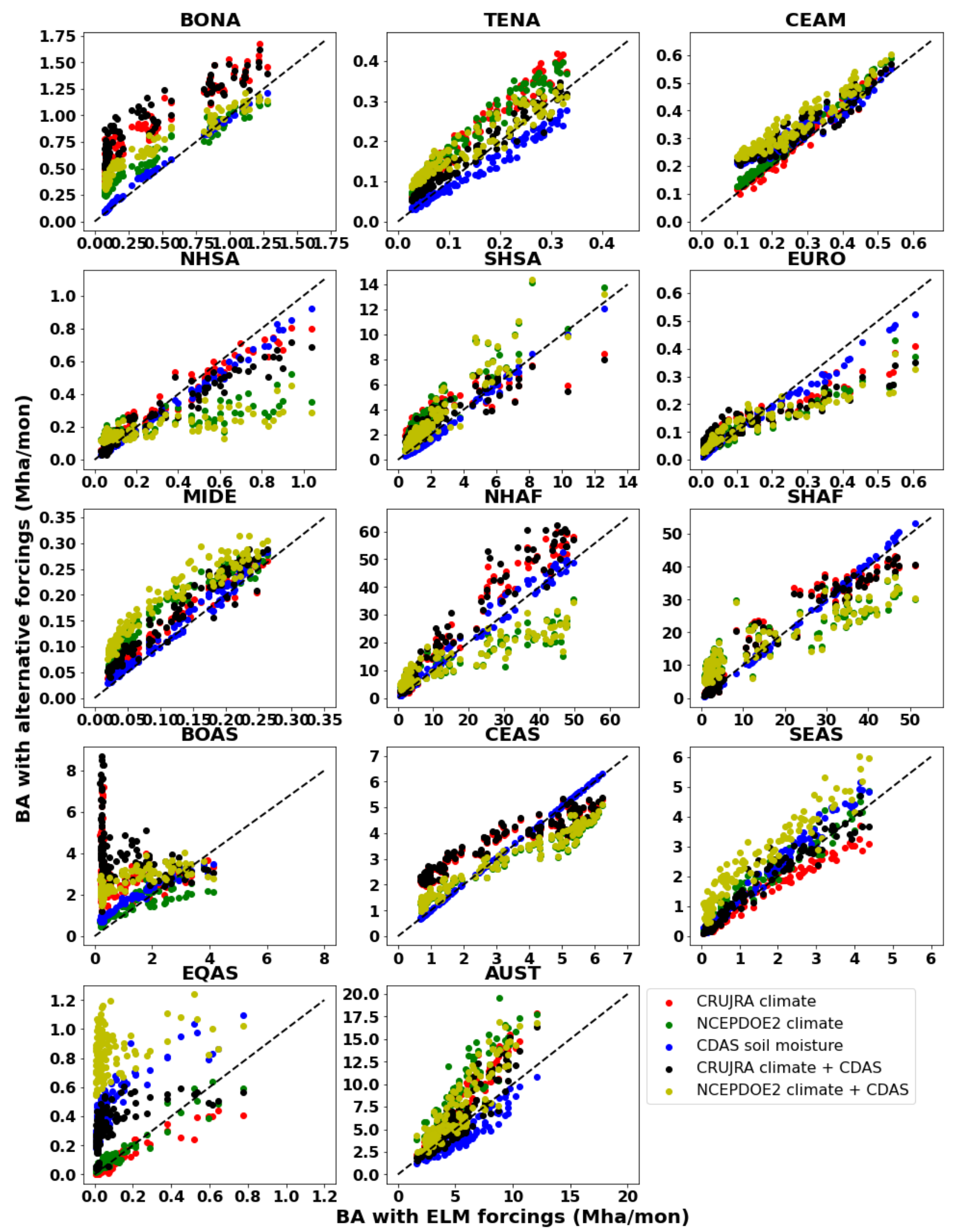

BA with ELM forcings (Mha/mon)

27 Figure S5. Sensitivity of modeled burned area (2001-2010 long-term averaged) to climate

28 forcings (including temperature, precipitation, wind speed, relative humidity) and soil moisture. 
$\mathrm{X}$-axis was burned area simulated by the default model using GSWP3 climate forcing and ELMv1 simulated soil moisture. Y-axis were models with alternative climate forcing (CRUJRA, NCEPDOE2) and soil moisture product (NCEP CDAS soil moisture).

33

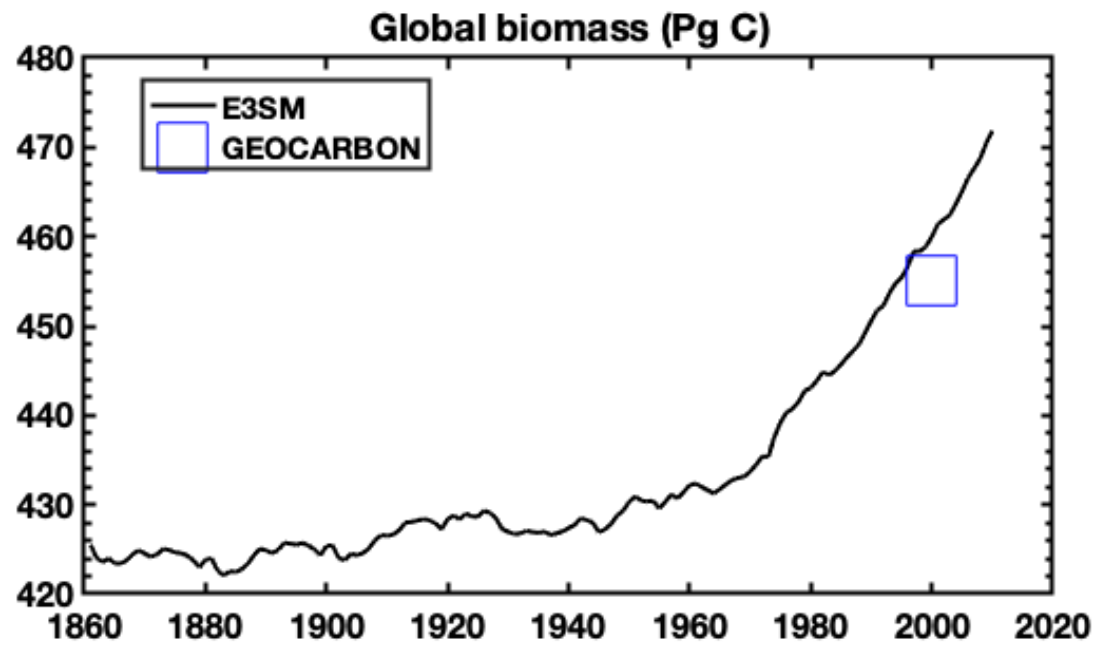

Figure S6. 3SM simulated global vegetation biomass [425-472 $\mathrm{PgC}]$ and observational based estimate of present-day living biomass (455 PgC GEOCARBON).

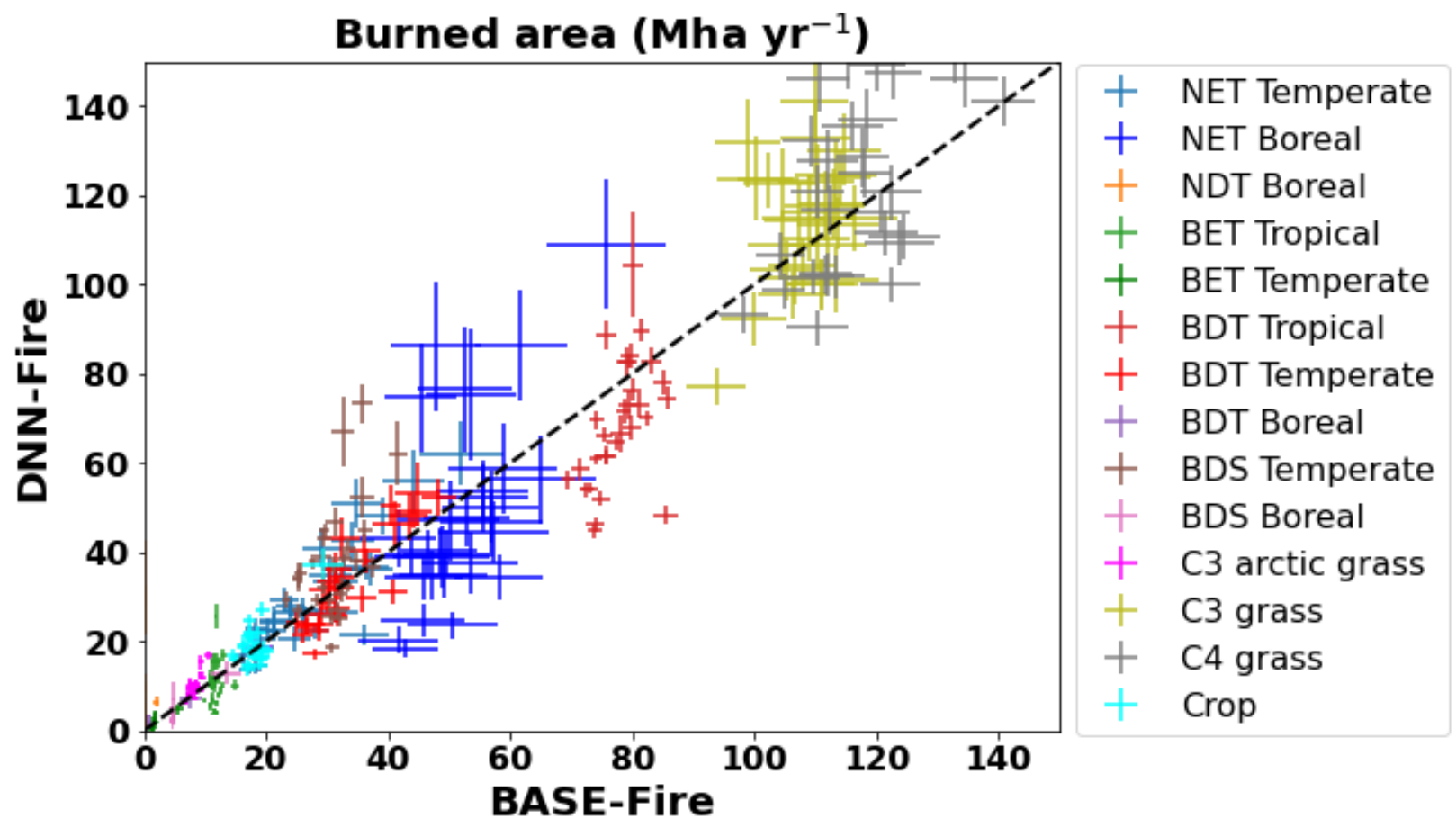

Figure S7. The performance of the Deep Neural Network wildfire model (DNN-Fire), compared with the original ELMv1 process-based wildfire model (BASE-Fire) aggregated over 14 plant functional types between years 2001 and 2010. 


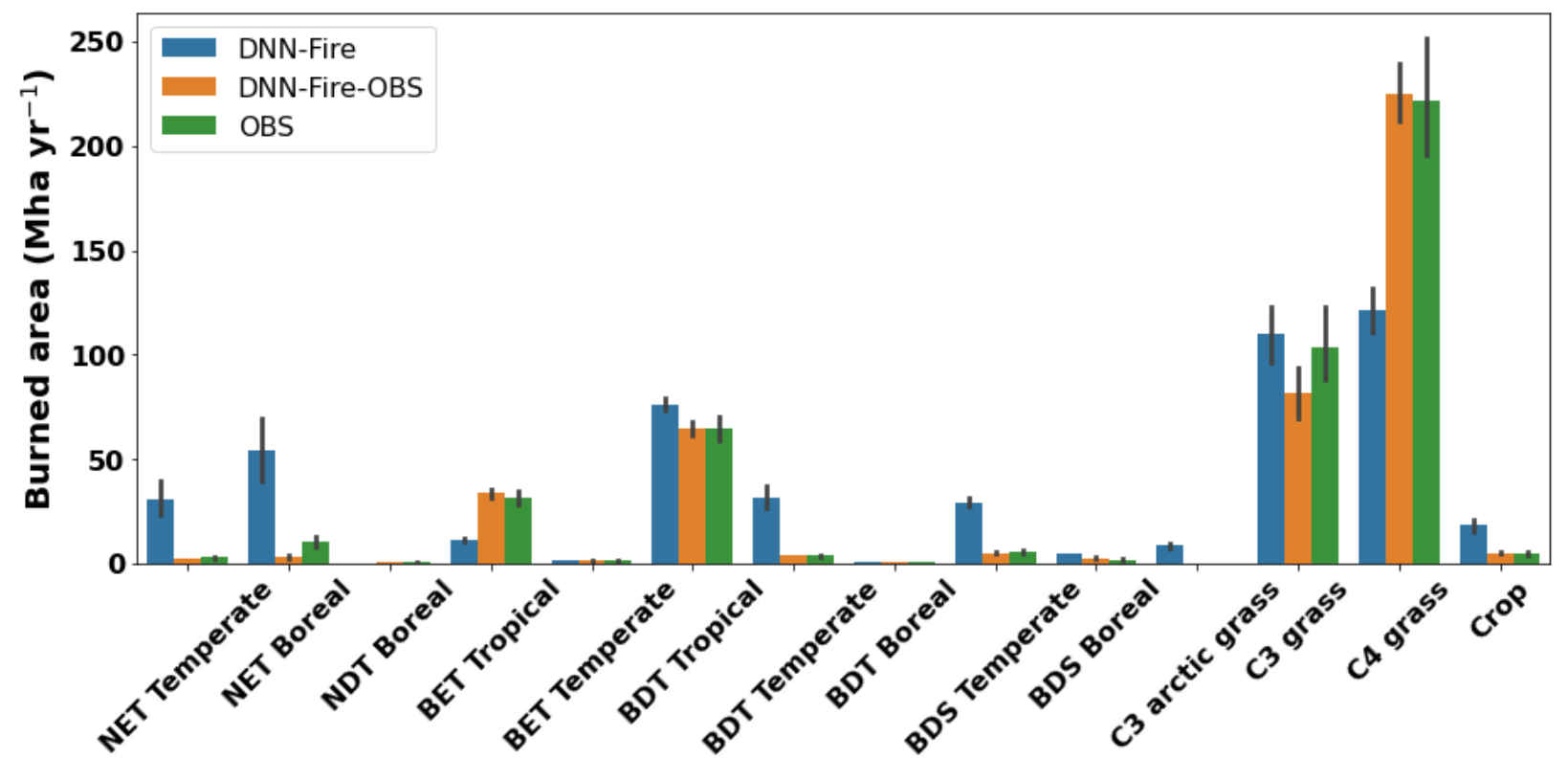

45 Figure S8. A comparison of wildfire burned area among Deep Neural Network wildfire model 46 (DNN-Fire), Deep Neural Network wildfire model fine-tuned with observed burned area (DNN47 Fire-OBS), and observations for 14 plant functional types. 